\title{
Mitral valve injury late after transcatheter aortic valve implantation
}

\author{
Daniel R. Wong, MD, MPH, ${ }^{a}$ Robert H. Boone, MD, MSc, ${ }^{b}$ Christopher R. Thompson, MD, ${ }^{\mathrm{b}}$ Michael F. Allard, MD, ${ }^{c}$ \\ Lukas Altwegg, MD, ${ }^{\mathrm{b}}$ Ronald G. Carere, MD, ${ }^{\mathrm{b}}$ Anson Cheung, MD, ${ }^{\mathrm{a}}$ Jian Ye, MD, ${ }^{\mathrm{a}}$ Samuel V. Lichtenstein, MD, PhD, ${ }^{\mathrm{a}}$ \\ Hilton Ling, MD, ${ }^{\mathrm{a}}$ and John G. Webb, MD, ${ }^{\mathrm{b}}$ Vancouver, British Columbia, Canada
}

Transcatheter aortic valve implantation (TAVI) is an alternative to high-risk aortic valve replacement (AVR). ${ }^{1,2}$ There are limited data on long-term outcomes.

\section{CLINICAL SUMMARY}

An 88-year-old man with symptomatic severe aortic stenosis underwent percutaneous TAVI with a 26-mm SAPIEN valve (Edwards Lifesciences LLC, Irvine, Calif). Comorbid conditions included coronary artery bypass with patent retrosternal grafts, transient ischemic attacks, bilateral carotid endarterectomies, atrial fibrillation, repaired abdominal aneurysm, prostate cancer, and renal failure. Estimated 30day mortality for AVR was $35 \%$ by means of logistic EuroSCORE and $11.1 \%$ by means of the Society of Thoracic Surgeons National Database Risk Calculator. The procedure was performed without difficulty, but the final valve position was suboptimal, being slightly low (ventricularly), with the ventricular aspect of the stent abutting the anterior leaflet of the mitral valve (MV). Moderate paravalvular aortic regurgitation (AR) was treated with repeated balloon redilation $^{3}$ without altering the valve position. Six-month transthoracic echocardiographic analysis showed trivial AR and mitral regurgitation.

The patient presented 11 months after implantation with fever and Streptococcus angiosus in blood cultures. Also noted were a dental visit 6 weeks before and lack of compliance with endocarditis prophylaxis. Transesophageal echocardiographic analysis demonstrated mild-to-moderate paravalvular AR, a $13 \times 8-\mathrm{mm}$ ruptured anterior mitral leaflet aneurysm contiguous with the aortic prosthesis, and severe mitral regurgitation (Figure 1).

Redo sternotomy was performed during cardiopulmonary bypass after cannulating the right axillary artery and right internal jugular vein. The bioprosthesis was well-seated below the coronary arteries with incomplete endothelialization of the uppermost struts and covered with nodular excrescences (Figure 2). It withstood extraction while fully expanded but was removable when grasped with forceps, which were

\footnotetext{
From the Divisions of Cardiac Surgery, ${ }^{\mathrm{a}}$ Cardiology, ${ }^{\mathrm{b}}$ and the Department of Pathology and Laboratory Medicine, ${ }^{\mathrm{c}}$ St Paul's Hospital, University of British Columbia, Vancouver, British Columbia, Canada.

Received for publication March 30, 2008; revisions received May 27, 2008; accepted for publication June 7, 2008.

Address for reprints: John G. Webb, MD, McLeod Professor of Heart Valve Disease Intervention, and Director, Interventional Cardiology, St Paul's Hospital, Room 5202A, 1081 Burrard St, Vancouver, BC, Canada V6Z 2E8 (E-mail: webb@ providencehealth.bc.ca).

J Thorac Cardiovasc Surg 2009;137:1547-9

$0022-5223 / \$ 36.00$

Copyright (C) 2009 by The American Association for Thoracic Surgery doi:10.1016/j.jtcvs.2008.06.018
}

twisted to crumple the stent. A 5-mm mitral perforation appeared to be related to the transcatheter stent and was repaired with bovine pericardium. AVR was performed with a 25-mm bioprosthesis and the continuous suture technique.

The postoperative course was complicated by renal failure, pneumonia, delirium, and dysphagia. The patient remained afebrile with a normal white blood cell count and was discharged home 38 days postoperatively.

Light microscopy revealed collagen delamination and acutely inflamed vegetational material on the transcatheter valve cuspal surface. Significant cusp infiltration by neutrophils and gram-positive cocci confirmed endocarditis (Figure 3).

\section{DISCUSSION}

Late complications of TAVI are largely unknown. Unlike MV laceration during antegrade transfemoral implantation, we describe late MV injury/perforation, endocarditis, and successful explantation of the transcatheter valve.

\section{TAVI Positioning}

Low TAVI positioning likely contributed to the outcome reported. Until now, emphasis has been on landing the aortic edge just cranial to the native aortic cusps to ensure fixation and coronary clearance. A strategy focusing equally on the ventricular and aortic extents of the stent and avoiding low positioning might be warranted. Increased valve visibility might also be beneficial. Although all transcatheter valves could be susceptible to this complication, longer valves extending further into the ventricle would seem to be at higher risk.

\section{Paravalvular Leak and Endocarditis}

Sequelae of AR include compromise to ventricular function, hemolysis, endocarditis, and MV leaflet aneurysm. ${ }^{5}$ Paravalvular leaks after TAVI are usually posteriorly located, possibly because of rigidity/calcification of the fibrous aortic annulus and anterior mitral leaflet (versus the more conformable muscular aortic annulus anteriorly). In this case the posterior jet possibly contributed to denuding the mitral endothelium, aneurysm formation, or both. A moderate or greater paravalvular leak warrants balloon redilation.

We believe this perforation was related to stent contact causing erosion, transmitting infection, or both. No other reports of MV perforation exist despite presumably low positioning in some, although this does not exclude significant contact-related mitral injury in the noninfective setting. Treatment of preexisting infections, preoperative dental consultation, and strict endocarditis prophylaxis are advisable. 

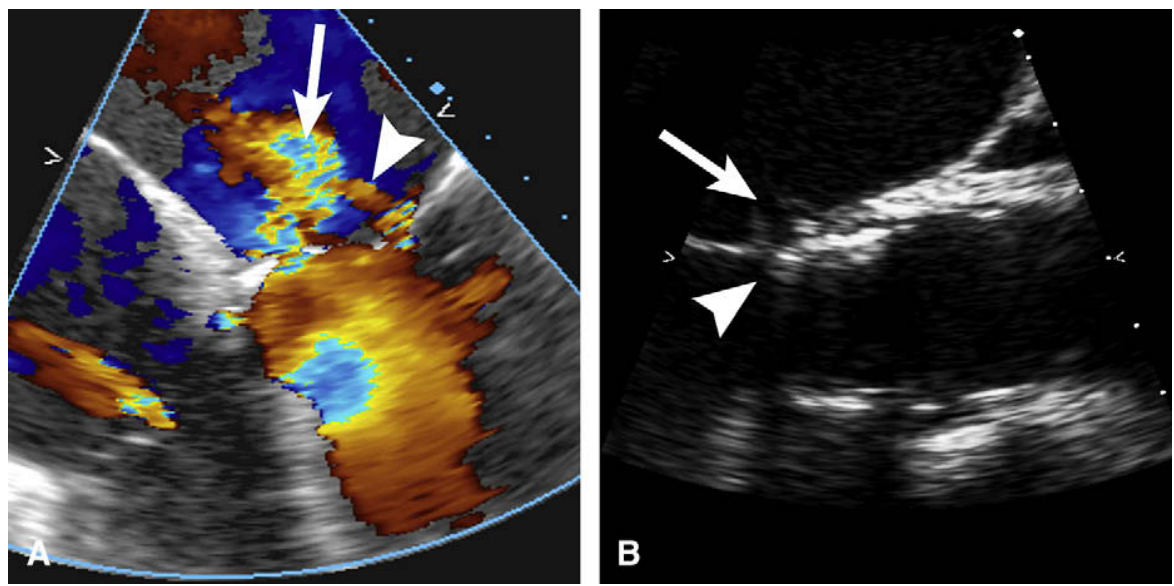

FIGURE 1. Transesophageal echocardiographic evaluation of late severe mitral regurgitation. A, Two regurgitant jets were identified, one transvalvular (arrow) and a second through a perforation in the anterior mitral leaflet (arrowhead). B, A ruptured aneurysm (arrow) of the anterior leaflet of the mitral valve was present adjacent to the ventricular edge (arrowhead) of the implanted transcatheter aortic valve.
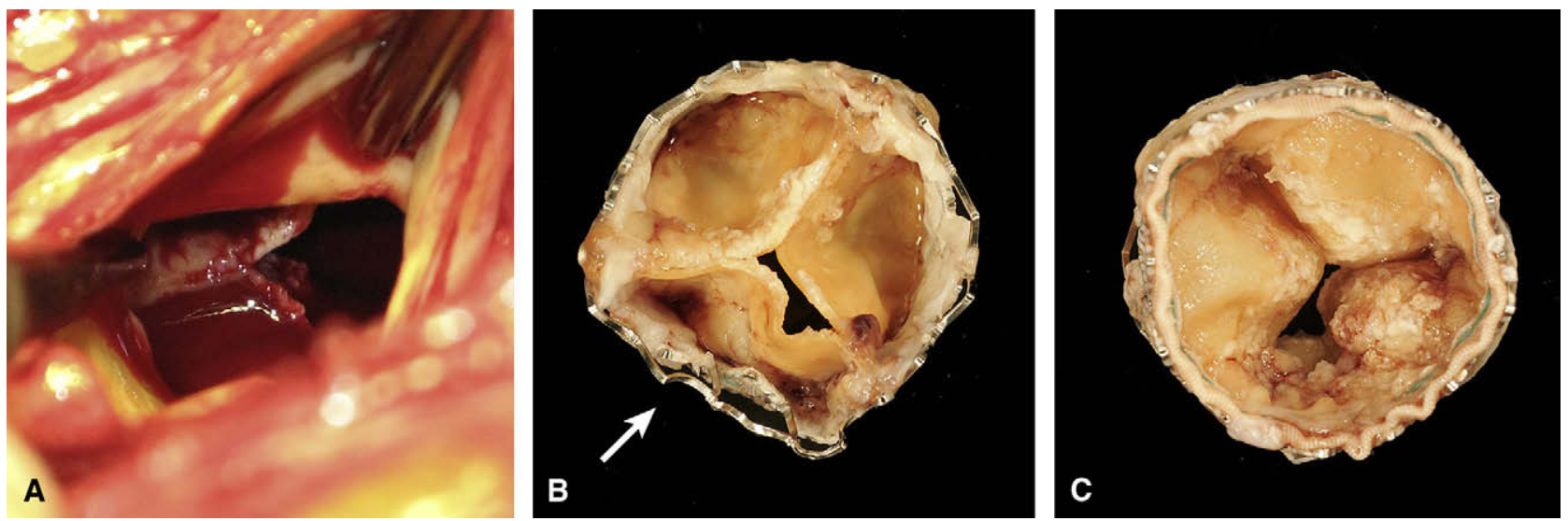

FIGURE 2. Infective endocarditis on the transcatheter aortic valve. A, Intraoperative view from the surgeon's perspective; the right side of the image is anterior, corresponding to a "right" transcatheter valve cusp in nearly standard orientation. B, Explanted transcatheter valve as seen from the aortic side in the same orientation as above. The cusps appeared thickened and covered with nodular endocarditic excrescences; the "noncoronary" portion of the valve stent (arrow) was deformed by the surgeon to facilitate explantation. The stent was crushed to explant it and reformed ex vivo, but the effects of surgical removal were still apparent. C, Explanted transcatheter valve as seen from the ventricular side showing similar features.
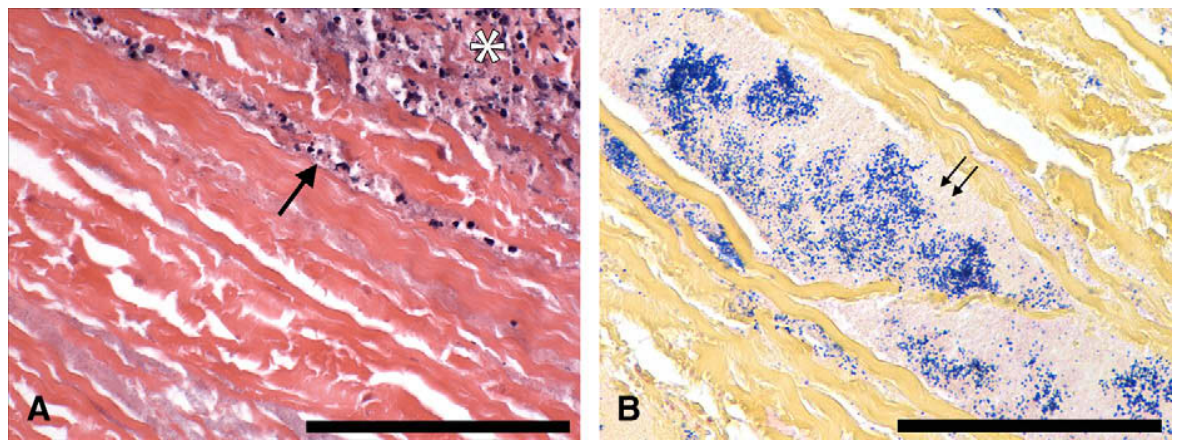

FIGURE 3. Representative light micrograph of percutaneous aortic valve cuspal tissue showing acutely inflamed vegetational material on the cusp surface (asterisk) with superficial permeation of cuspal tissue by inflammatory cells (arrow; A) and coccal bacteria within tissue planes of the cusp (double arrow; B). A, Hematoxylin and eosin stain; B, Gram stain. Bar is representative of $100 \mu \mathrm{m}$ in each image. 


\section{No Need for Root Replacement}

Explantation of a SAPIEN valve is feasible, followed by standard AVR without root replacement. In contrast, other transcatheter valves more broadly fixed to the left ventricular outflow tract, root, and/or tubular aorta might require more complex high-risk operations after explantation.

\section{Valve Stability and Pseudoendothelialization}

Fears of calcium resorption leading to loss of valve fixation over the intermediate term are likely unfounded. In this patient, despite minimal initial native aortic cusp calcification, the valve was tenaciously fixed. Whether tissue in-growth contributed is unclear. This valve, particularly the uncovered upper stent cells, was not fully covered in pseudoendothelium 11 months later. Although beneficial near the coronary ostia (possibly caused by high flow), retarded pseudoendothelialization might require antiplatelet therapy postoperatively. Paravalvular leak might further disrupt tissue coverage. Finally, cusp integrity was lost early, probably accelerated by infection and high flow with (paravalvular) AR. Further evaluation of long-term durability, function, and tissue coverage is needed.

We thank Lise Matzke for assistance with obtaining the light micrograph and gross specimen images.

\section{References}

1. Webb JG, Chandavimol M, Thompson CR, Ricci DR, Carere RG, Munt BI, et al. Percutaneous aortic valve implantation retrograde from the femoral artery. Circulation. 2006;113:842-50.

2. Lichtenstein SV, Cheung A, Ye J, Thompson CR, Carere RG, Pasupati S, et al Transapical transcatheter aortic valve implantation in humans: initial clinical experience. Circulation. 2006;114:591-6.

3. Pasupati S, Sinhal A, Humphries K, Ivens E, Moss R, Thompson CR, et al. Re-dilation of balloon expandable aortic valves [BEAV]: what do we know? Am J Cardiol. 2007;100(suppl I):57L.

4. Hanzel GS, Harrity PJ, Schreiber TL, O’Neill WW. Retrograde percutaneous aortic valve implantation for critical aortic stenosis. Catheter Cardiovasc Interv. 2005;64: 322-6.

5. Raval AN, Menkis AH, Boughner DR. Mitral valve aneurysm associated with aortic valve endocarditis and regurgitation. Heart Surg Forum. 2002;5:298-9.

\title{
A new subspecialty in cardiac surgery: Scrap metal merchant
}

\author{
Giuseppe Rescigno, MD, ${ }^{\mathrm{a}}$ Marco Pozzi, MD, FRCS, FETCS, ${ }^{\mathrm{a}}$ Filippo Capestro, MD, ${ }^{\mathrm{a}}$ Luciano S. Matteucci, MD, ${ }^{\mathrm{a}}$ \\ Christopher Münch, MD, ${ }^{\mathrm{b}}$ Gianfranco Iacobone, MD, ${ }^{\mathrm{a}}$ and Gian Piero Piccoli, MD, ${ }^{\mathrm{a}}$ Ancona, Italy
}

The future of cardiac surgery is an ongoing debate, prompted by the dramatic development of percutaneous techniques that actually reduce the indications for standard surgical treatments. ${ }^{1,2}$ During the last 6 months, we have been faced with 4 cases of complications from percutaneous procedures related to entrapment of foreign bodies or lesions due to mechanical devices. Our main goal has been to retrieve these devices and treat the underlying cardiac disease.

\section{CLINICAL SUMMARIES Patient 1}

A 72-year-old man was scheduled for placement of elective left anterior descending artery stent in another hospital. The patient had an atheromatous left common trunk. During the procedure, the stent was entrapped at this level. The patient was therefore transferred to our hospital. Under cardiopulmonary bypass (CPB) and cardioplegic arrest, we

\footnotetext{
From the Departments of Cardiac Surgery ${ }^{\mathrm{a}}$ and Cardiac Anesthesia, ${ }^{\mathrm{b}}$ Lancisi HospitalOspedali Riuniti di Ancona, Ancona, Italy.

Received for publication Dec 29, 2007; accepted for publication Jan 8, 2008.

Address for reprints: Giuseppe Rescigno, MD, Via Santa Maria del Fiore 62, 60030

Morro d'Alba, Italy (E-mail: grescigno@libero.it).

J Thorac Cardiovasc Surg 2009;137:1549-50

0022-5223/\$36.00

Copyright (c) 2009 by The American Association for Thoracic Surgery

doi:10.1016/j.jtcvs.2008.01.049
}

removed the stent through the aorta (Figure 1). A complete revascularization was performed by means of bilateral internal thoracic artery grafting.

\section{Patient 2}

A 74-year-old man who had a percutaneous coronary intervention (PCI) on a diagonal branch was referred to our department because of an entrapped guide wire at the level of the left common trunk, despite the endovascular attempt to retrieve it. The patient was operated on, and under CPB and cardioplegic arrest, the guide wire was removed by a combined approach through the aorta and an arteriotomy of the diagonal vessel. A left internal thoracic artery graft was therefore implanted on the diagonal branch.

\section{Patient 3}

A 65-year-old man was admitted to our surgical department with chest pain. He had undergone a transcatheter patent forame ovale closure with a 25-mm Amplatzer occluder 1 year prior. The transesophageal echocardiogram (TEE) performed showed "penetration" of the left atrial disk of the occluder into the left atrial wall and the posterior wall of the aortic root. A magnetic resonance image demonstrated an extravasation of the dye from the left atrial cavity into the 